\title{
Application of laser cladding technology to improve the interface of thermal barrier coatings
}

\author{
Ma Yue,* Duan Zhuping, Yang Zhixing and Wu Chengkang \\ LNM, Institute of Mechanics, The Chinese Academy of Sciences, Beijing 100080, People's Republic of China
}

\begin{abstract}
The present study is focused on improvement of the adhesion properties of the interface between plasmasprayed coatings and substrates by laser cladding technology (LCT). Within the laser-clad layer there is a gradient distribution in chemical composition and mechanical properties that has been confirmed by SEM observation and microhardness measurement. The residual stress due to mismatches in thermal and mechanical properties between coatings and substrates can be markedly reduced and smoothed out. To examine the changes of microstructure and crack propagation in the coating and interface during loading, the three-point bending test has been carried out in SEM with a loading device. Analysis of the distribution of shear stress near the interface under loading has been made using the FEM code ANSYS. The experimental results show clearly that the interface adhesion can be improved with LCT pretreatment, and the capability of the interface to withstand the shear stress as well as to resist microcracking has been enhanced. Copyright (C) 2000 John Wiley \& Sons, Ltd.
\end{abstract}

KEYWORDS: laser cladding technology; thermal barrier coatings; interface

\section{INTRODUCTION}

The resistance of materials against mechanical wear, corrosion, oxygenation, thermal shock, etc. can be improved by plasma-sprayed coatings on the surface of substrate, and this technique has been widely used for space and civil components. ${ }^{1-4}$ However, some shortcomings exist in the plasma-sprayed coatings due to the presence of micropores, microcracks and poor adhesion properties between coatings and substrates. These faults largely restrict the application of this technique..$^{5-7}$ Recently, the coating qualities have been improved by modifying the processing parameters and adjusting the heat treatment parameters, ${ }^{8-10}$ but the poor interface adhesion properties have not been solved yet. ${ }^{11}$ The rupture usually takes place near the interface where residual stress and defects exist due to the thermal and mechanical mismatch. The improvement in the interface properties plays a key role in using plasma spraying technology, because it significantly affects the global strength of the material.

The present paper aims at providing a laser cladding process to improve the interface behaviour of $\mathrm{ZrO}_{2}$ thermal barrier coatings. Before plasma spraying, the process of laser cladding was conducted on the surface of the substrate. The thickness of the laser cladding layer that formed on the interface between coating and substrate is $\sim 10-20 \mu \mathrm{m}$. Within the laser-clad layer there is a gradient distribution in chemical composition and mechanical

* Correspondence to: M. Yue, LNM, Institute of Mechanics, The Chinese Academy of Sciences, Beijing 100080, People's Republic of China.

E-mail: mayue62@hotmail.com

Contract/grant sponsor: National Natural Science Foundation; Contract/grant number: 19891180-4.

Contract/grant sponsor: Foundation of the Chinese Academy of Sciences; Contract/grant number: K-951-1-201. performance, and this has been confirmed by SEM observation and microhardness measurement. ${ }^{12}$ Experimental results show that because there is a transition region, the adhesion strength and resistance to crack propagation can be improved and the global strength of the materials can be increased.

\section{EXPERIMENTAL}

The substrate material is the Ni-based DZ22 superalloy, and its composition is: C, $0.12-0.16 \%$; $\mathrm{Cr}, 8.0-10.05 \%$; Co, 9.0-11.0\%; W, 11.5-12.5\%; Al, 4.75-5.25\%; Ti, 1.75-2.25\%; Fe, <0.35\%; Nb 0.75-1.25\%; Hf, 1.0-2.0\%; B, $0.01-0.02 \%$; $\mathrm{Zr},<0.01 \%$; Mn, <0.20\%; Si, $<0.2 \%$. The coating material is $\mathrm{ZrO}_{2}+(6-8 \mathrm{wt} . \%) \mathrm{Y}_{2} \mathrm{O}_{3}$ and the cladding layer material is $40 \%(\mathrm{Ni}+\mathrm{Al})+60 \% \mathrm{ZrO}_{2}$. First, the cladding layer material mixed with epoxy was brushed onto the surface of the substrate, the cladding process was conducted using a $2 \mathrm{~kW} \mathrm{HJ}-4 \mathrm{CO}_{2}$ laser device and the laser cladding layer is formed on the surface of the substrate. Finally, some mixed powder of $\mathrm{ZrO}_{2}+(6-8 \mathrm{wt} . \%) \mathrm{Y}_{2} \mathrm{O}_{3}$ was coated by plasma spraying on the surface of the substrate that was pretreated by laser cladding technology (LCT).

In order to investigate the effect of LCT on the adhesion properties of the interface between coatings and substrates, two kinds of substrate specimens were used: one processed by LCT and the other unprocessed. All the samples were of dimensions $75 \times 15 \times 1 \mathrm{~mm}$. The plasma spraying process was taken with the following parameters: power of plasma torch $=35 \mathrm{~kW}$; spray distance $=80 \mathrm{~mm}$; spray rate of the powder $=50 \mathrm{~g} \mathrm{~min}^{-1}$; diameter of nozzle $=$ $6.3 \mathrm{~mm}$. The protection gas is used as $\mathrm{Ar}+\mathrm{H}_{2}+\mathrm{N}_{2}$. The $\mathrm{ZrO}_{2}$ thermal barrier coating is $0.3 \mathrm{~mm}$ thick.

The microstructures of the coating and the compositions of the cladding layer were analysed with a Stereoscan 


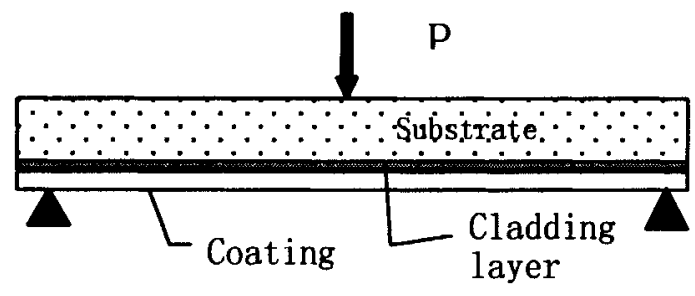

Figure 1. The three-point bending sample.

360 scanning electron microscope and EDAX. Samples $(21 \times 4 \times 1 \mathrm{~mm})$ for the three-point bending test (see Fig. 1) were cut out of the central section of every coated sample, and their length direction was parallel to that of laser scanning. Two groups of three-point bending samples, with and without the laser cladding layer (LCL), were tested by using SEM with a loading device, and there were four samples used for each group. A representative result was taken from each group test. Microhardness was measured using a microhardness meter with a POLYVAR MER microscope, and mechanical analysis of the stress distribution in various samples under loading was conducted with the commercial FEM code ANSYS.

\section{RESULTS AND DISCUSSION}

\section{Three-point bending tests}

Three-point bending tests were conducted for two groups of the coated samples-one with the LCL and the other without - and the character of the coating and interface under various loading conditions is displayed in Fig. 2.

The experimental results show that at the beginning [zero load, Fig. 2(a)] no crack can be detected within the samples without an LCL. Gradually, with the increase of the load, microcracks appear at the interface between coatings and substrates, and when the load is up to $50 \mathrm{~N}$

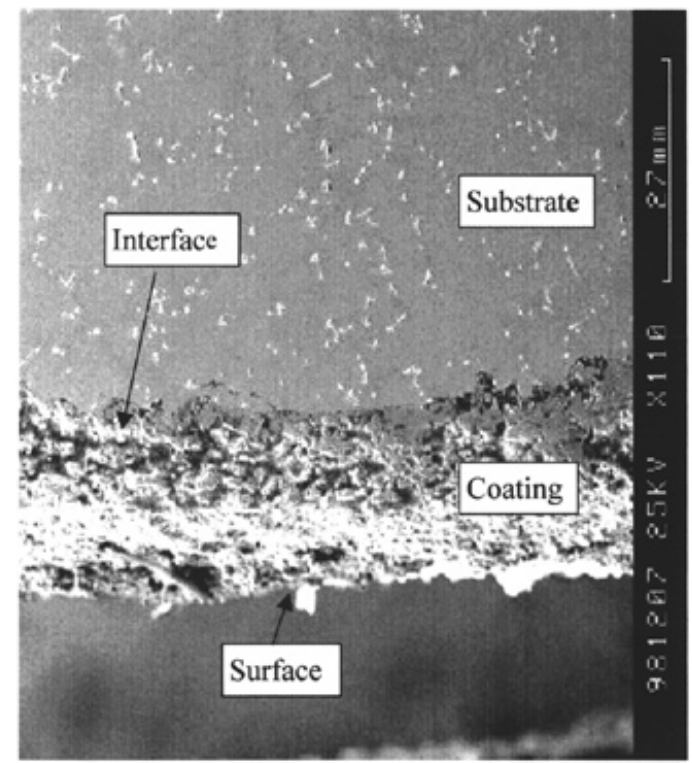

(a)
[Fig. 2(b)] a large crack forms from coalescence of a group of the microcracks near the interface, and the coating is torn away from the substrate. For the samples with an LCL, when the load is $\sim 50 \mathrm{~N}$ a few cracks appear within the interface layer near the loading area of the samples. Only when the load reached $63.2 \mathrm{~N}$ did a large crack appear at the interface near the loading zone on the samples, and the coating was torn away from the substrate. A crack within the substrate near the interface was formed and its direction is perpendicular to the interface.

\section{Analysis of the LCL}

The distribution of microhardness and composition within the LCL is given in Fig. 3, where it can be seen that the content of $\mathrm{Zr}$ gradually decreases along the thickness direction from the surface of the LCL to the substrate, and the microhardness changes in the same manner. This shows that a gradient layer near the surface of the substrate can be formed by LCT.

\section{Analysis of stress distribution at the interface under loading}

The deformation of the three-point bending sample under loading is simplified as a plane strain problem, and Young's modulus and the Poisson ratio for the materials used in the numerical analysis are given:

$$
\begin{aligned}
& \text { DZ22 : } E=198 \mathrm{GPa}, \quad v=0.336 \\
& \mathrm{ZrO}_{2}: \quad E=51 \mathrm{GPa}, \quad v=0.333
\end{aligned}
$$

It is assumed that the elastic moduli are linear with respect to the thickness within the LCL. The stress field in the sample is calculated with the commercial FEM code ANSYS; the distribution of the shear stress at the interface between coating and substrate is illustrated in Fig. 4.

The distribution of the shear stress at the interface is symmetrical with respect to the central line in the

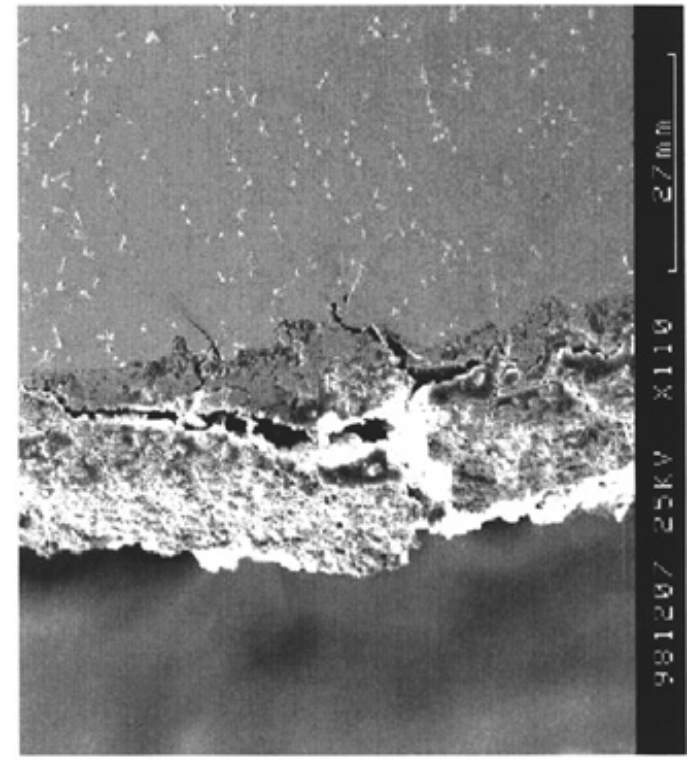

(b)

Figure 2. Adhesion of the interface between coating and substrate: (a, b) without laser cladding layer; (c-e) with laser cladding layer. The load is: $(a, c)$ zero; $(b, d) \sim 50 \mathrm{~N} ;(e) \sim 63.2 \mathrm{~N}$. 


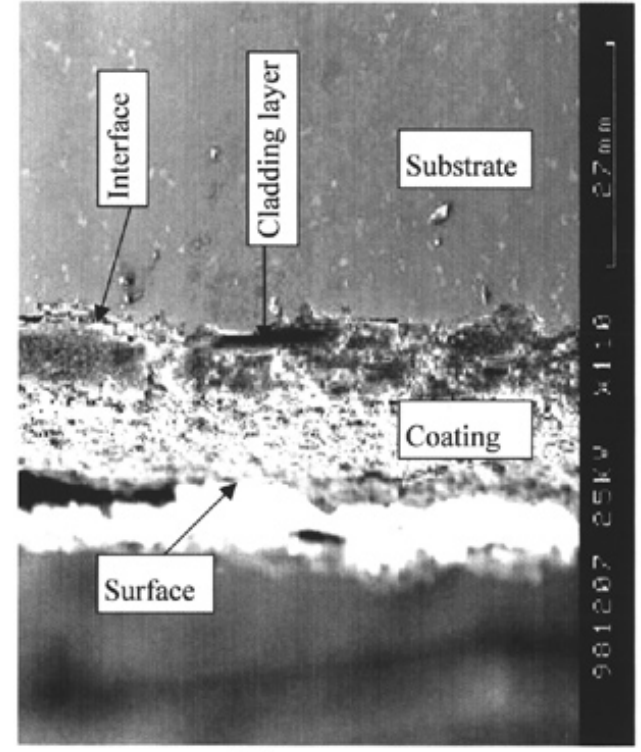

(c)

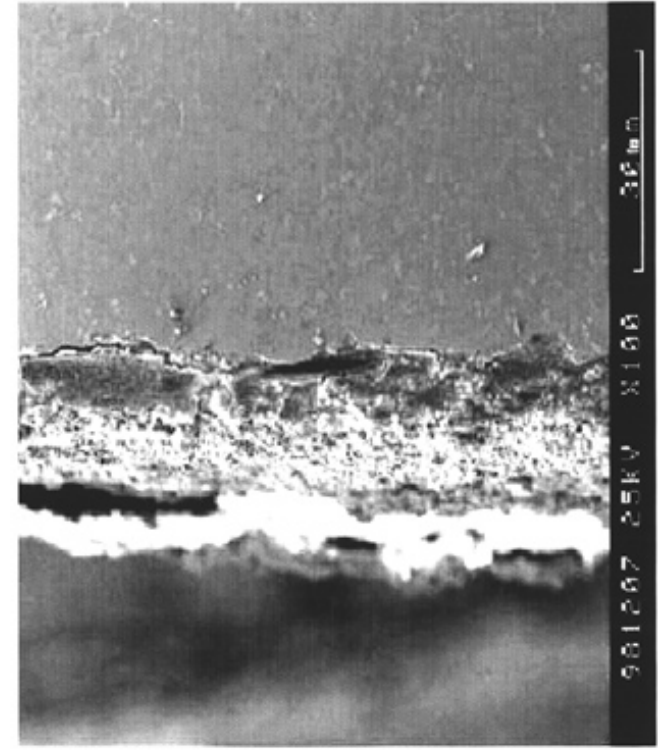

(d)

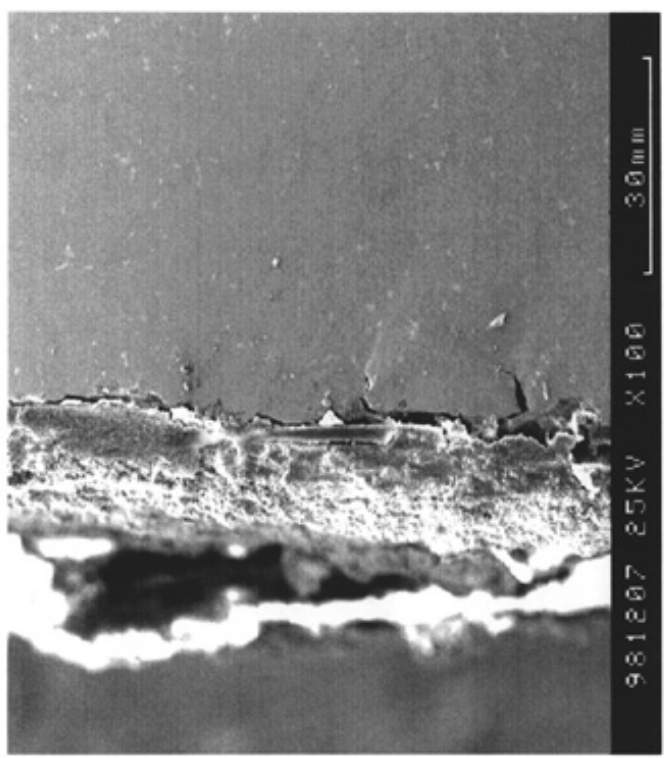

(e)

Figure 2. (continued).

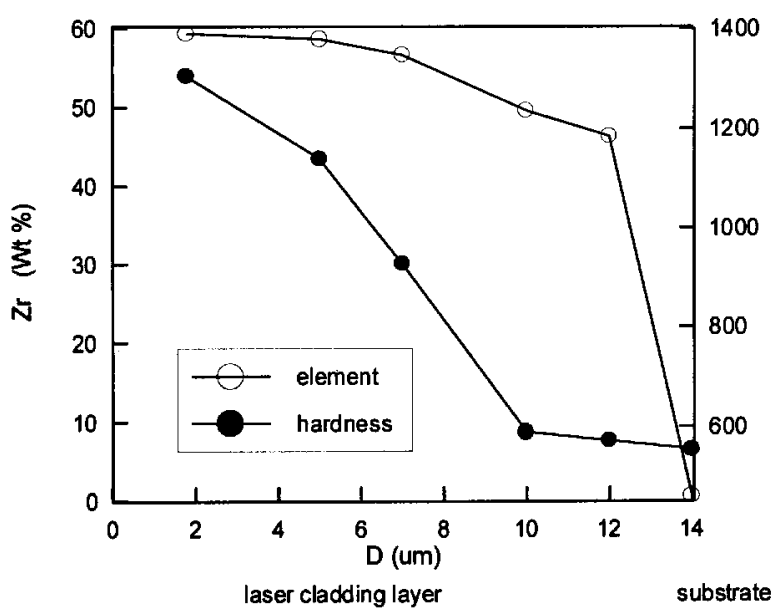

Figure 3. The $\mathrm{Zr}$ distribution and hardness distribution within the laser cladding layer; $D$ is the distance from the surface of the laser cladding layer. longitudinal direction in both groups of samples, i.e. with LCL and without. There is a maximum stress gradient in the middle part of the sample, i.e. the area of loading, so the interface crack and coating rupture firstly take place there.

The capability of the interface to sustain the shear stresses is different for different samples. According to the dimensions of the experimental specimens and the corresponding critical loads the maximum shear stress that the samples can withstand at the interface is $2.77 \mathrm{MPa}$ for samples without an LCL and 5.61 MPa for those with an LCL; the latter is significantly higher than the former.

\section{Role of the LCL in improving the adhesion properties between the coating and substrate}

The distribution of $\mathrm{Zr}$ and the microhardness are graded within the LCL obtained by pretreating the surface of the 


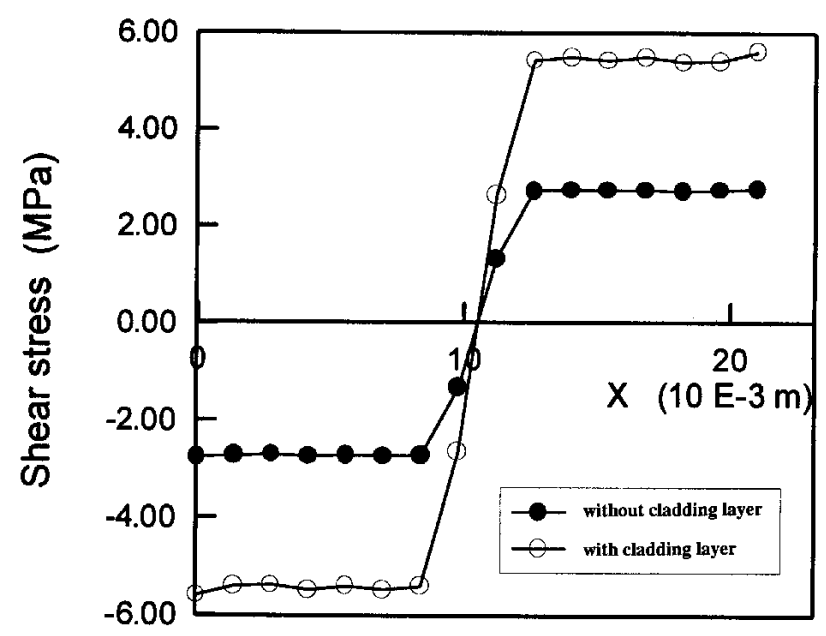

Figure 4. Capability of withstanding shear stress in the substrate/coating interface; $X$ is the direction of the length of the sample.

substrate using LCT. The residual stress due to mismatch in the thermal and mechanical properties between the coating and the substrate can be markedly reduced and the change of microstructure and properties from the coating to the substrate can be smoothed out. Adhesion of the layer obtained by LCT and the substrate is metallurgical. The adhesion area between the coating and substrate has been increased because there is a laser-induced coarsening on the surface of the substrate. Thus, the adhesion character at the coating/substrate interface and the ability of the withstanding load can be improved.

\section{CONCLUSION}

From the present study, we can conclude:

(1) The LCT developed here can provide a useful means in plasma-spraying coating technology for a pretreatment on the surface of a substrate. An LCL is formed by this technique between the coating and the substrate, and the experimental results show that a gradient distribution in the composition of $\mathrm{Zr}$ and the microhardness is formed within the LCL.

(2) Because of the presence of such a gradient transient layer of $10-20 \mu \mathrm{m}$ thick between the coating and the substrate, the residual stress will reduce within the layer and the adhesion strength as well as the capabilities to sustain external loading at the interface are improved clearly in comparison with those without LCT pretreatment.

\section{Acknowledgements}

The authors are grateful to Professor Wenbiao Wang, Doctor Chenguang Huang, Rongjing Zhang, Yongzhi Chen and Duanyi Li for helping in the calculations and test work. This work was supported by the National Natural Science Foundation of China (no. 19891180-4) and the Foundation of the Chinese Academy of Sciences (K-951-1-201).

\section{REFERENCES}

1. Gu YW, Khor KA, Fu YQ, Wang Y. Surf. Coat. Technol. 1997; 96: 305.

2. Xiang XH, Zhu JC, Yin ZG, Lai JG. Surf. Coat. Technol. 1996; 88: 66.

3. Pei YT, Ouyang JH, Lei TC. Surf. Coat. Technol. 1996; 81: 131.

4. Liu ZL, Ding ZX, Huang WL. Surf. Technol. 1997; 4: 4.

5. Kobayashi A. Surf. Coat. Technol. 1997; 90: 197.

6. Hu W, Guan H, Sun X, Li S. Surf. Coat. Technol. 1998; 105: 102.
7. Zeng XT, Zhang S, Hsieh J. Surf. Coat. Technol. 1998; 102: 108.

8. Bull SJ, Jones AM. Surf. Coat. Technol. 1996; 78: 173.

9. Liang GY, Wong TT. Surf. Coat. Technol. 1997; 89: 121.

10. Hsu IC, Wu SK. Surf. Coat. Technol. 1997; 90: 6.

11. Movchan BA, Marinski GS. Surf. Coat. Technol. 1998; 100: 309.

12. Wolf B, Paufler P. Surf. Interface Anal. 1999; 27: 592. 